\title{
Epstein-Barr virus-related hemophagocytic lymphohistiocytosis complicated with coronary artery dilation and acute renal injury in a boy with a novel X-linked inhibitor of apoptosis protein (XIAP) variant: a case report
}

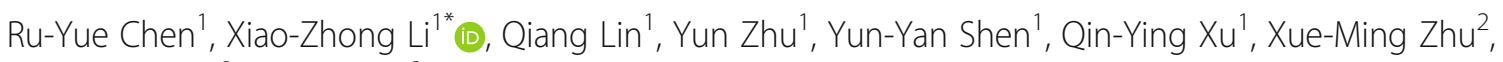
Zhen-Jiang $\mathrm{Bai}^{3}$ and Ying $\mathrm{Li}^{3}$

\begin{abstract}
Background: X-linked lymphoproliferative disease (XLP) is a rare inherited X-linked primary immunodeficiency diseases (PID). One such disease, $X$-linked inhibitor of apoptosis protein (XIAP) deficiency, is characterized by Epstein-Barr virus-related hemophagocytic lymphohistiocytosis (EBV-HLH). However, EBV-HLH with coronary artery dilation and acute renal injury (AKI) in children is unusual.

Case presentation: We report the case of a young boy aged 17 months with a novel XIAP variant. He was initially diagnosed with EBV-HLH based on the HLH-2004 diagnostic criteria and the condition was accompanied by coronary artery dilation and acute renal injury. The comprehensive genetic analysis of peripheral blood-derived DNA revealed a hemizygous variant of the XIAP gene [c.116G > C(p.G39A)], which was inherited from his mother (heterozygous condition). After combined treatment with rituximab, intravenous immunoglobulin, corticosteroids, antiviral drugs, and mycophenolate mofetil (MMF) in addition to supportive therapy, his clinical manifestations and laboratory indexes were improved. The patient achieved complete remission with MMF treatment in the 8-month follow-up.

\footnotetext{
* Correspondence: xiaozhonglicn@yeah.net

'Department of Nephrology and Immunology, Children's Hospital of Soochow University, Suzhou, Jiangsu, China

Full list of author information is available at the end of the article
}

(c) The Author(s). 2020 Open Access This article is licensed under a Creative Commons Attribution 4.0 International License, which permits use, sharing, adaptation, distribution and reproduction in any medium or format, as long as you give appropriate credit to the original author(s) and the source, provide a link to the Creative Commons licence, and indicate if changes were made. The images or other third party material in this article are included in the article's Creative Commons licence, unless indicated otherwise in a credit line to the material. If material is not included in the article's Creative Commons licence and your intended use is not permitted by statutory regulation or exceeds the permitted use, you will need to obtain permission directly from the copyright holder. To view a copy of this licence, visit http://creativecommons.org/licenses/by/4.0/ The Creative Commons Public Domain Dedication waiver (http://creativecommons.org/publicdomain/zero/1.0/) applies to the data made available in this article, unless otherwise stated in a credit line to the data. 
(Continued from previous page)

Conclusions: We report the [c.116G > C(p.G39A)] variant in the XIAP gene for the first time in a case of XLP-2 associated with EBV-HLH. For male patients with severe EBV-HLH, the possibility of XLP should be considered and molecular genetic testing should be used early in auxiliary diagnosis. Reports of EBV-HLH with coronary artery dilation and AKI in children are rare. In the patients with EBV-HLH, color Doppler echocardiography and urine tests should be monitored regularly. If necessary, renal biopsy can be performed to clarify the pathology. Treatment with rituximab, immunosuppressors and supportive therapy achieved a good effect, but long-term follow-up is required.

Keywords: X-linked inhibitor of apoptosis protein (XIAP), Hemophagocytic lymphohistiocytosis (HLH), Epstein-Barr virus (EBV), Coronary artery dilatation, Acute renal injury (AKI)

\section{Background}

$\mathrm{X}$-linked lymphoproliferative disease (XLP) is a rare inherited X-linked primary immunodeficiency disease (PID), which has two recognizable subtypes identified by the $X L P-1$ and $X L P-2$ gene variants. XLP-1 is caused by variants in the $S H 2 D 1 A$ gene, which maps to the $\mathrm{X}$ chromosome (Xq25-26) and contains four exons coding for the signaling lymphocytic activation moleculeassociated protein (SAP) that is involved in immune cell activation. XLP-2 is caused by variants in the XIAP gene, also known as the BIRC4 gene $[1,2]$. XIAP is located close to $S H 2 D 1 A$ on the X-chromosome and contains six exons that encode the X-linked inhibitor of apoptosis (XIAP) protein [1]. Both of these variants are associated with defective immune responses to Epstein-Barr virus (EBV) infection [3]. Here, we report the case of a young boy with cardiovascular and renal lesions who was diagnosed with EBV-positive hemophagocytic lymphohistiocytosis (EBV-HLH) secondary to an underlying XIAP gene variant [c.116G > C(p.G39A)].

\section{Case presentation}

A small boy aged 17 months (body weight, $10 \mathrm{~kg}$; height, $88 \mathrm{~cm}$; ethnicity, Chinese) was admitted to the Infection Department of our hospital for persistent fever lasting 8 days. Neither the boy nor his family had a significant history of conditions such as cancer, inflammatory bowel disease (IBD), and autoimmune diseases. However, the mother had a history of gestational diabetes, hypothyroidism and anemia during pregnancy, which improved after 2 months of active treatment.

After 4 days of anti-infective treatment, the child still had a high fever and presented with lethargy, abdominal distention, oliguria and vomiting. The auxiliary examination suggested that multiple organs were involved and multiple serous cavity effusion was present. The child was transferred to our department and more relevant examinations were applied. He developed a high fever, polyserositis (pelvic, pleural, peritoneal and pericardial effusion), anemia (hemoglobin (Hb) $70 \mathrm{~g} / \mathrm{L}$ ), hyperferritinemia $(1149.4 \mathrm{ng} / \mathrm{ml})$, hypertriglyceridemia $(4.65 \mathrm{mmol} /$ L), obvious elevated soluble CD25 $(5783.3 \mathrm{pg} / \mathrm{ml}$; reference range: 400-2500 pg/ml), mildly increased IL-6 $(10.3 \mathrm{pg} / \mathrm{ml}$; reference range: $0-2.2 \mathrm{pg} / \mathrm{ml})$ and IL-10 $(12.8 \mathrm{pg} / \mathrm{ml}$; reference range: $0-2.3 \mathrm{pg} / \mathrm{ml})$. The proportion of CD3-CD56 ${ }^{+}$cells was $1.2 \%$ (reference range: $3.3-$ $32.3 \%$ in lymphocyte). Killer cell immunoglobulin (Ig)like receptor (KIR) expression and function in NK cells was normal. EBV shell and early antigen IgG antibody were positive, with low affinity of capsid antigen. High EBV DNA loads in peripheral blood and serum $(6.69 \times$ $10^{4}$ copies $/ \mathrm{ml}$ and $<5.0 \times 10^{2}$ copies $/ \mathrm{ml}$, respectively) suggested a diagnosis of EBV-HLH based on the HLH2004 diagnostic criteria. Bone marrow biopsy was negative for hemophagocytes. Hemolysis tests and ADAM TS13 activity were normal. Other pathogen detection tests such as blood culture, sputum culture, T-SPOT, and mycoplasma antibody tests were negative. Color Doppler echocardiography indicated coronary artery dilatation with mild pericardial effusion and valvular regurgitation (Table 1). The progressive increase in serum creatinine and decrease in estimated glomerular filtration rate $\left(e G F R=9 \mathrm{ml} / \mathrm{min} / 1.73 \mathrm{~m}^{2}\right.$ according to the Schwartz equation), combined with oliguria, persistent proteinuria and hematuria suggested acute kidney disease (AKI). Due to the young age of the child, it was difficult to collect 24-h urine; therefore, 24-h urine protein quantification was not performed. Comprehensive genetic analysis (full exhome sequencing) of peripheral blood-derived DNA revealed that the patient carried a hemizygous variant of XIAP (NG_ 007264.1, NM_ 001167, NP_001158.2). The maternal missense variant c.116G > C in exon 2 leads to an amino acid change (p.G39A), which has never been reported previously and is absent from controls (1000 Genomes, ExAC, gno$\mathrm{mAD}$, and $\mathrm{CNGB}$ ). SIFT program predicts that the variant is damaging (score $0.012<0.05$ ), which might affect normal functions of the protein [4]. According to the standard of American College of Medical Genetics (ACMG) [5], variant c.116G $>\mathrm{C}$ is classified as Variant of Uncertain Significance (VUS) of XIAP. However, the patient in our study presented with typical clinical phenotypes of EBV-HLH. In addition, we didn't have identified any other mutations that were associated with this 
Table 1 Color Doppler echocardiography

\begin{tabular}{|c|c|c|c|c|c|c|c|c|c|c|c|}
\hline \multirow[t]{2}{*}{ Time } & \multirow[t]{2}{*}{$\mathrm{EF} \%$} & \multirow[t]{2}{*}{$\mathrm{FS} \%$} & \multicolumn{7}{|c|}{ Coronary artery diameter (mm) } & \multirow[t]{2}{*}{ Hydropericardium } & \multirow[t]{2}{*}{ Cardiac valves } \\
\hline & & & LMCA & $\mathbf{Z}$ & LAD & $\mathrm{Z}$ & $\begin{array}{l}\text { Proximal } \\
\text { RCA }\end{array}$ & $\mathbf{Z}$ & $\begin{array}{l}\text { Aortic } \\
\text { annulus }\end{array}$ & & \\
\hline $1 d$ & 80 & 50 & 2.2 & 0.91 & - & - & 1.7 & 0.22 & 10 & - & - \\
\hline $8 d$ & 68 & 37 & 2.3 & 1.19 & 2.1 & 1.98 & 1.7 & 0.19 & 10 & Mild & $\begin{array}{l}\text { Mild regurgitation of mitral valve, tricuspid valve } \\
\text { and aortic valve }\end{array}$ \\
\hline $11 d$ & 66 & 36 & 2.5 & 1.75 & 2.3 & 2.58 & 2.5 & 2.38 & 11.6 & Mild & $\begin{array}{l}\text { Mild regurgitation of mitral valve, tricuspid valve } \\
\text { and aortic valve }\end{array}$ \\
\hline $27 d$ & 72 & 40 & 2.4 & 1.47 & 2.3 & 2.58 & 2.1 & 1.29 & 11.6 & - & - \\
\hline $40 d$ & 70 & 39 & 2.5 & 1.71 & 2.3 & 2.54 & 2.2 & 1.52 & 10.3 & - & - \\
\hline $78 d$ & 63 & 33 & 2.5 & 1.63 & 2.2 & 2.17 & 2.1 & 1.17 & 11.6 & - & - \\
\hline $132 d$ & 68 & 37 & 2.4 & 1.27 & 2.0 & 1.51 & 2.1 & 1.1 & 12 & - & - \\
\hline
\end{tabular}

LMCA Left main coronary artery, Proximal RCA Proximal right coronary artery, $L A D$ Left anterior descending artery

disease of the patient. Thus, we predicted that the variant c.116G > C of XIAP should be responsible for EBVHLH.

After 1 month of a treatment regimen including intravenous immunoglobulin $(2 \mathrm{~g} / \mathrm{kg})$, methylprednisolone pulse $(\mathrm{MP} ; 20 \mathrm{mg} / \mathrm{kg} . \mathrm{d} \times 3 \mathrm{~d}, 8 \mathrm{mg} / \mathrm{kg}$.d and then gradually reduced), antibiotics, antiviral drugs (acyclovir and ganciclovir sequentially), rituximab $(0.1 \mathrm{~g})$, aspirin, and urokinase in addition to supportive therapy, the patient's clinical manifestations and laboratory indexes were obviously improved except for coronary artery dilatation, persistent proteinuria $(2+-3+)$ and hematuria. Renal biopsy was then performed (Figs. 1, 2 and 3). Under light microscopy, the glomeruli showed mild mesangial hyperplasia combined with vacuolar degeneration and atrophy of epithelial cells in some renal tubules, and dilatation of the tubular lumen. Extended extracellular matrix with scattered infiltration of lymphocytes and slight fibrosis suggested chronic renal tubulointerstitial inflammation. Immunofluorescence analysis showed

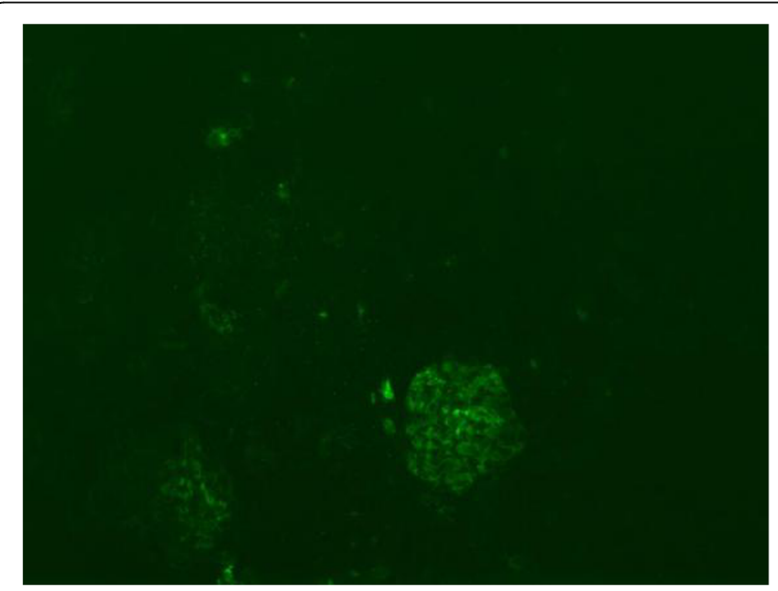

Fig. 1 Immunofluorescence of renal biopsy (×100). Focal deposition of immunoglobulin-M in glomerular mesangium and capillary loops focal deposition of IgM in glomerular mesangium and capillary loops. Under electron microscopy, the glomerular capillary basement membrane was thin (160-280 $\mathrm{nm}$ ), with segmental fusion of epithelial podocytes, and no electron dense deposition. The patient's treatment was continued with mycophenolate mofetil (MMF) and 5 days later, his urine protein test was negative, although hematuria continued. After 3 months, color Doppler echocardiography showed no obvious dilation of the coronary artery. After 6 months, the hematuria was in remission and the child had a good prognosis in the regular 8 month follow-up.

\section{Discussion and conclusion}

$\mathrm{X}$-linked lymphoproliferative disease (XLP) is a rare form of X-linked PID, that occurs in two forms known as XLP-1 and XLP-2 [6]. The annual incidence of XLP is approximately $2-3$ cases per million, of which XLP-1 accounts for more cases than XLP-2 [6]. In China, the onset of XLP is usually at 1-60 months of age, and is often triggered by EBV infection [1]. Other viral infections, such as human herpes virus 6, cytomegalovirus, have also been reported in association with XLP, although cases without an identifiable infectious agent have also been described $[7,8]$. The life-threatening manifestations of XLP triggered by EBV include EBV-positive hemophagocytic lymphohistiocytosis (EBV-HLH), chronic active EBV infection (CAEBV) and EBV-positive lymphoma [3].

\section{Clinical manifestation}

XLP-1 and XLP-2 patients differ in terms of several clinical features. Patients with XLP-1 develop recurrent splenomegaly and IBD very rarely, while patients with XLP-2 do not develop lymphoma. Hypogammaglobulinemia is common to XLP-1 and XLP-2 [7]. HLH is common in XLP-2, and often recurrent [2, 6, 9]. According to an international survey, approximately $55 \%$ of patients 


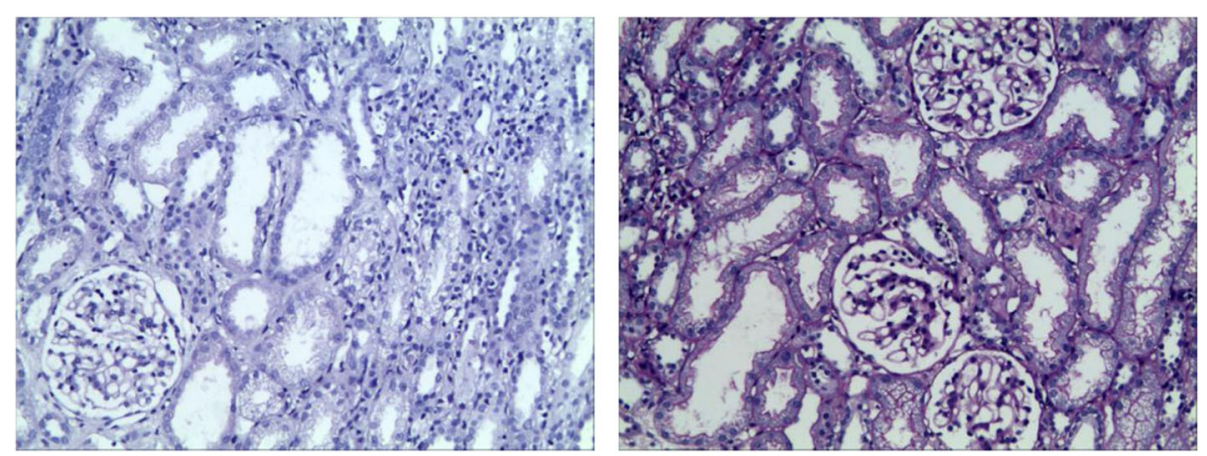

Fig. 2 Light microscopy of renal biopsy (×100). Mild mesangial hyperplasia in glomeruli; vacuolar degeneration and atrophy of epithelial cells in some renal tubules; chronic inflammation of stroma, scattered infiltration of lymphocytes and slight hyperplasia of fibers

with XLP-2 developed HLH and 26\% presented with IBD, which was lower that the HLH frequency in Japan (79\%), France $(71 \%)$ and the USA $(82 \%)[7,10]$. In a genetic study of 265 Chinese patients with $\mathrm{HLH}$, genetic variants were observed in $87(32.83 \%)$ patients, of which $10(11.49 \%)$ had variants in XLAP and six (6.90\%) carried variants in SH2D1A [11]. EBV infection has been reported to be a trigger of the first HLH episode in patients with XIAP deficiency (30-70\% of cases) $[6,8,9]$. The comprehensive genetic analysis of peripheral bloodderived DNA in our case revealed a hemizygous variant of the XIAP gene [c.116G >C(p.G39A)], which was inherited from the patient's mother (heterozygous condition). The patient was diagnosed with EBV-HLH based on the HLH-2004 diagnostic criteria according to clinical manifestations and relevant examinations, which

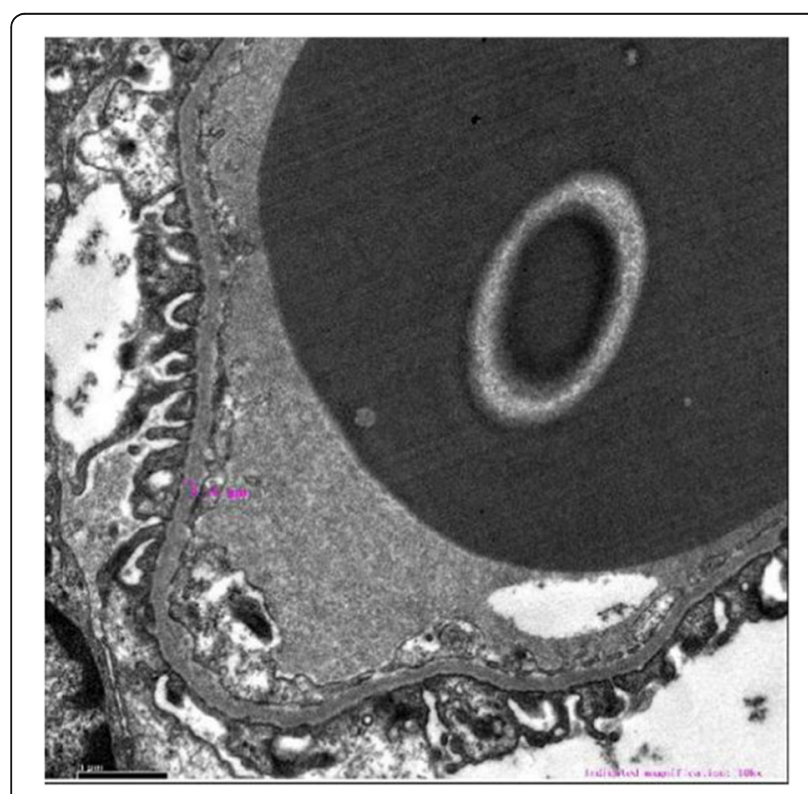

Fig. 3 Electron microscopy of renal biopsy $(\times 10,000)$. Glomerular capillary basement membrane are thin segmentally $(160-280 \mathrm{~nm})$ was consistent with the characteristics of the XIAP gene variant. Family history provides critical information for the identification of XLP; however, the child in this case had no family history of IBD or lymphomas.

\section{Cardiovascular complications}

In this case, the boy developed recurrent fever and relevant examinations suggested the diagnosis of EBV-HLH with coronary artery lesions similar to Kawasaki disease (KD). However, the patient lacked the typical symptoms of $\mathrm{KD}$, such as skin rash, conjunctivitis, swelling or desquamation of the extremities. As stated previously, both KD and EBV-HLH are autoinflammatory diseases complicated by immunologic dysfunction. There is considerable overlap between these conditions in terms of pathophysiology, such as increased serum levels of IL-6, IL- 8 , TNF- $\alpha$ and soluble IL-2 receptor [12]. Some studies indicated that EBV-infected $\mathrm{CD}^{+} \mathrm{T}$ cells and high levels of the cytokines in EBV-HLH may play some role in development of coronary artery lesions [12, 13]. Recent studies have shown that the serum levels of soluble CD163 and the soluble tumor necrosis factor receptor II/I ratio were significantly elevated in patients with EBV-HLH compared to those in patients with acutephase KD [14, 15]. At present, reports of EBV-HLH with cardiovascular complications in children are rare although the cases of two Japanese girls, aged 3- and 4years have been published. In terms of cardiovascular complications, the 3-year-old girl presented as left main coronary artery dilatation, which improved after treatment with cyclosporine, dexamethasone and etoposide [12], while the 4-year-old presented with acute myocarditis and coronary aneurysms, which improved after rituximab treatment [13]. Both children had good prognosis after long-term follow-up. See BT et al. reported the case of an 8-year-old girl from Malaysia presented with EBV-HLH associated with a giant aneurysm and ectasia of the coronary arteries [16]. The coronary lesions improved after 6 months of treatment with 
dexamethasone and etoposide. Sun G et al. reported a 10-year-old Chinese girl who was diagnosed with EBVHLH with cardiac complications, including pericardial effusion (PE) and coronary artery aneurysms (CAAs) [17]. After 2 weeks, ultrasonic cardiograms revealed that the PE disappeared and no marked changes in the CAAs following treatment with dexamethasone, etoposide, aspirin and persantin. After 10 months, the PE did not reoccur and there were no obvious changes in the CAAs. However, CAEBV with cardiovascular complications has been reported in a relatively large number of patients, with the coronary artery disease being the most common complication [18-20].

\section{Renal lesions}

In our case, the patient's condition was manifested as oliguria, persistent proteinuria and hematuria. The progressive increase in serum creatinine level and decreased eGFR suggested acute kidney disease (AKI), which in this case may be accounted for as follows: (1) Severe storms of inflammatory cytokines result in polyserositis and hypovolemia, which cause renal hypoperfusion. Aulagnon $\mathrm{F}$ et al. [21] reported that the main causes of AKI during HLH were acute tubular necrosis (49\%), hypoperfusion (46\%), tumor lysis syndrome $(29 \%)$, or HLH-associated glomerulopathies (17\%). It has been reported that the leading causes of EBV-related AKI include rhabdomyolysis and hepatic failure [22]. The prerenal factors can lead to AKI. (2). Application of nephrotoxic drugs preceding treatments such as antibiotics can cause renal injury [23]. (3) Hyperactivated cytotoxic T-lymphocytes and macrophages cause direct damage to kidney tissue. Ozgurhan $\mathrm{G}$ et al. reported that the renal biopsy in a child with EBV infection showed intense and mixed tubulointerstitial inflammatory infiltration that was rich with $\mathrm{T}$ cells and histiocytes [24]. The renal biopsy in our case showed mild mesangial hyperplasia of the glomeruli, lymphocyte infiltration and mild fibrosis of the renal interstitium under light microscopy. Suzuki J et al. reported an adult case of fulminant EBV infection with AKI. In situ hybridization of EBVencoded RNA 1 did not show the presence of the virus in the kidney and AKI was thought to be caused by cytokine secretion from activated cytotoxic $\left(\mathrm{CD}^{+}\right) \mathrm{T}$ lymphocytes [23]. Moretti $M$ et al. systematically reviewed 38 patients with primary EBV infectious mononucleosis complicated by AKI, including 27 cases of acute interstitial nephritides (AIN), three of hemolytic uremic syndromes, one of jaundice-associated nephropathy and seven of myositides [25]. Mansur A et al. [26] performed immunohistochemical staining of renal tissue from 78 patients with EBV infection and AIN and identified a positive correlation between CD68 macrophage infiltration and serum creatinine concentration, as well as expression of IL-4, eotaxin, CCR3, CCR5 and VCAM-1 in biopsies from patients with AIN. In addition, EBV was not detected by in situ hybridization and immunohistochemistry analyses in any of the AIN sections, indicating that EBV is not a pathogenetic factor in AIN [26]. In addition to AIN, EBV-related renal lesions include glomerular abnormalities such as immune-complex mediated glomerulonephritis, membranous nephropathy, minimal change nephritic syndrome and IgA nephropathy, which are very rare [27-29]. Renal biopsy immunofluorescence analysis in our case showed focal IgM deposition in the glomerular mesangium and capillary loops. (4) In situ hybridization analysis has revealed direct EBV infection in renal proximal tubular cells in patients with idiopathic chronic tubulointerstitial nephritis [30], indicating that EBV directly damages renal tissue.

\section{Treatment and prognosis}

In cases of XLP-related EBV-HLH, EBV-infected cells are predominantly B cells [3]. Therefore, in our case, combination therapy of rituximab and ganciclovir was administered, which cleared the EBV DNA titers and relieved symptoms. It has been reported that immunosuppressive medication such as corticosteroids are not effective against this virus-associated tubulointerstitial nephritis [23]. In our case, serum creatinine and eGFR returned to normal, urine protein tests became negative, and hematuria was improved after treatment with corticosteroids and MMF. Renal replacement therapy can be given in the acute stage of renal injury. It has been reported that $47 \%$ of patients with EBV infection and AKI required renal replacement therapy, although $90 \%$ can be relieved [25]. However, it has also been reported that the incidence of AKI during HLH is $62 \%$, with $59 \%$ cases requiring renal replacement therapy and chronic kidney disease in $32 \%$ at 6 months [21]. Other treatments for XLP include antiviral agents, anti-IFN- $\gamma$ and $\alpha$, intravenous immunoglobulins, etoposide, and $\mathrm{T}$ cell immunosuppression, but the only curative therapy is allogeneic hematopoietic stem cell transplantation (HSCT) $[1,8,10]$. It is recommended that HSCT should be performed as soon as possible for patients with EBV-HLH, hypogammaglobulinemia, lymphoma or aplastic anemia, because the outcome without HSCT is extremely poor [1]. However, the child in our case had stable vital signs, and his laboratory indexes and color Doppler echocardiography trend gradually returned to normal after the treatment of intravenous immunoglobulin, methylprednisolone, antibiotics, antiviral drugs, rituximab, aspirin, and urokinase in addition to supportive therapy, without HSCT. It is necessary to him closely in the long-term in case of disease progression or recurrence.

We report the case of a 17-month-old boy diagnosed with EBV-HLH complicated by cardiac and renal lesions. 
Reports of EBV-HLH with coronary artery and renal complications in children are relatively rare. Color Doppler echocardiography and urine tests were monitored regularly. Renal biopsy was performed to clarify the pathology. The application of rituximab, immunosuppressants and corticosteroids combined antiviral drugs had a good effect. The genetic analysis determined a novel hemizygous variant of the XIAP gene [c.116G > C(p.G39A)]. For male patients with severe EBV-HLH, the possibility of XLP should be considered and molecular genetic testing should be performed early in the auxiliary diagnosis.

\section{Abbreviations \\ XIAP: X-linked inhibitor of apoptosis protein; XLP: X-linked lymphoproliferative disease; PID: Primary immunodeficiency diseases; EBV- HLH: Epstein-Barr virus-positive hemophagocytic lymphohistiocytosis; EBV: Epstein-Barr virus; HLH: Hemophagocytic lymphohistiocytosis; AKI: Acute kidney disease; MMF: Mycophenolate Mofetil; SAP: Signaling lymphocytic activation molecule-associated protein; BIRC4: Baculoviral IAP repeat-containing protein 4; IBD: Inflammatory bowel disease; KIR: Killer cell immunoglobulin (Ig)-like receptor; ACMG: American College of Medical Genetics; VUS: Variant of Uncertain Significance; MP: Methylprednisolone pulse; CAEBV: Chronic active EBV infection; KD: Kawasaki disease; PE: Pericardial effusion; CAAs: Coronary artery aneurysms; AIN: Acute interstitial nephritides; HSCT: Hematopoietic stem cell transplantation}

\section{Acknowledgments}

We thank all the patients, families, and referring physicians who participated in this study. We also thank the Children's Hospital of Soochow University, Guangzhou jinyu Medical Laboratory Center, Beijing jinzhun Gene Technology company and Jiajian Check Medical Testing Corporation for their support.

\section{Authors' contributions}

RYC coordinated the research and wrote the manuscript. XZL designed and commented on the manuscript draft. QL helped to draft the manuscript. YZ, YYS and QYX coordinated collection of DNA samples, undertook genetic counseling and analyzed those data. XMZ provided pathology data and analyzed those data. ZJB and YL provided specialist advice and participated in the drafting and design of the manuscript. All authors read and approved the final manuscript.

\section{Funding}

This study was funded by the National Natural Science Foundation of China (81370787) and the Jiangsu Province Clinical Medical Science and Technology Commission (SBL2014030237). The funder commented on the manuscript draft.

\section{Availability of data and materials}

Data were collected from Children's Hospital of Soochow University, Guangzhou jinyu Medical Laboratory Center, Beijing jinzhun Gene Technology company and Jiajian Check Medical Testing Corporation. These data are reliable and available.

\section{Ethics approval and consent to participate}

All procedures performed in studies involving human participants were in accordance with the ethical standards of the institutional and/or national research committee. Informed consent was obtained from all individual participants included in the study.

\section{Consent for publication}

Written informed consent was obtained from the patient and his parents for publication of this Case report and any accompanying images. A copy of the written consent is available for review by the Editor of this journal.

\section{Competing interests}

The authors declare that there is no conflict of interest.

\section{Author details}

'Department of Nephrology and Immunology, Children's Hospital of Soochow University, Suzhou, Jiangsu, China. 'Department of Pathology, Children's Hospital of Soochow University, Suzhou, Jiangsu, China. ${ }^{3}$ Pediatric Intensive Care Unit, Children's Hospital of Soochow University, Suzhou, Jiangsu, China.

Received: 26 April 2020 Accepted: 24 September 2020

Published online: 02 October 2020

\section{References}

1. Jin YY, Zhou W, Tian ZQ, Chen TX. Variable clinical phenotypes of X-linked lymphoproliferative syndrome in China: report of five cases with three novel mutations and review of the literature. Hum Immunol. 2016;77(8):658-66.

2. Yang X, Kanegane H, Nishida N, Imamura T, Hamamoto K, Miyashita R, Imai K, Nonoyama S, Sanayama K, Yamaide A, et al. Clinical and genetic characteristics of XIAP deficiency in Japan. J Clin Immunol. 2012;32(3):411-20.

3. Ishimura M, Eguchi K, Shiraishi A, Sonoda M, Azuma Y, Yamamoto H, Imadome Kl, Ohga S. Systemic Epstein-Barr virus-positive T/NK Lymphoproliferative diseases with SH2D1A/XIAP Hypomorphic gene variants. Front Pediatr. 2019;7:183.

4. Choi Y, Sims GE, Murphy S, Miller JR, Chan AP. Predicting the functional effect of amino acid substitutions and indels. PLoS One. 2012;7(10):e46688.

5. Richards S, Aziz N, Bale S, Bick D, Das S, Gastier-Foster J, Grody WW, Hegde M, Lyon E, Spector E, et al. Standards and guidelines for the interpretation of sequence variants: a joint consensus recommendation of the American College of Medical Genetics and Genomics and the Association for Molecular Pathology. Genet Med. 2015;17(5):405-24.

6. Guo X, Li Q, Gao J. Langerhans cell histiocytosis complicated with hemophagocytic lymphohistiocytosis in a boy with a novel XIAP mutation: a case report. Medicine (Baltimore). 2018;97(44):e13019.

7. Aguilar C, Latour S. X-linked inhibitor of apoptosis protein deficiency: more than an X-linked lymphoproliferative syndrome. J Clin Immunol. 2015;35(4): 331-8.

8. Latour S, Aguilar C. XIAP deficiency syndrome in humans. Semin Cell Dev Biol. 2015;39:115-23.

9. Pachlopnik SJ, Canioni D, Moshous D, Touzot F, Mahlaoui N, Hauck F, Kanegane H, Lopez-Granados E, Mejstrikova E, Pellier I, et al. Clinical similarities and differences of patients with X-linked lymphoproliferative syndrome type 1 (XLP-1/SAP deficiency) versus type 2 (XLP-2/XIAP deficiency). Blood. 2011;117(5):1522-9.

10. Ono S, Okano T, Hoshino A, Yanagimachi M, Hamamoto K, Nakazawa Y, Imamura T, Onuma M, Niizuma H, Sasahara Y, et al. Hematopoietic stem cell transplantation for XIAP deficiency in Japan. J Clin Immunol. 2017;37(1):85-91.

11. Chen $X$, Wang F, Zhang $Y$, Teng W, Wang M, Nie D, Zhou X, Wang D, Zhao $H$, Zhu P, et al. Genetic variant spectrum in 265 Chinese patients with hemophagocytic lymphohistiocytosis: molecular analyses of PRF1, UNC13D, STX11, STXBP2, SH2D1A, and XIAP. Clin Genet. 2018;94(2):200-12.

12. Kato S, Yoshimura K, Tanabe Y, Kimata T, Noda Y, Kawasaki H, Kaneko K. A child with Epstein-Barr virus-associated hemophagocytic lymphohistiocytosis complicated by coronary artery lesion mimicking Kawasaki disease. J Pediatr Hematol Oncol. 2013;35(7):e317-9.

13. Kawamura Y, Miura H, Matsumoto Y, Uchida H, Kudo K, Hata T, Ito Y, Kimura $\mathrm{H}$, Yoshikawa T. A case of Epstein-Barr virus-associated hemophagocytic lymphohistiocytosis with severe cardiac complications. BMC Pediatr. 2016; 16(1):172.

14. Sakumura N, Shimizu M, Mizuta M, Inoue N, Nakagishi Y, Yachie A. Soluble CD163, a unique biomarker to evaluate the disease activity, exhibits macrophage activation in systemic juvenile idiopathic arthritis. Cytokine. 2018;110:459-65.

15. Shimizu M, Inoue N, Mizuta M, Nakagishi Y, Yachie A. Characteristic elevation of soluble TNF receptor || : I ratio in macrophage activation syndrome with systemic juvenile idiopathic arthritis. Clin Exp Immunol. 2018;191(3):349-55.

16. See $B T$, Yip $K X$, Ang $H L$. Is coronary arteritis a feature in secondary haemophagocytic lymphohistiocytosis? Paediatr Int Child Health. 2018;38(1): 76-9.

17. Sun G, Yao F, Yang Z. A pediatric case report of Epstein-Barr virus-associated Hemophagocytic Lymphohistiocytosis with pericardial effusion and multiple coronary artery aneurysms. J Pediatr Hematol Oncol. 2019. 
18. Ba H, Xu L, Peng H, Lin Y, Li X, Wang H, Qin Y. Chronic active Epstein-Barr virus infection with systemic Vasculitis and pulmonary arterial hypertension in a child. Front Pediatr. 2019;7:219.

19. Muneuchi J, Ohga S, Ishimura M, Ikeda K, Yamaguchi K, Nomura A, Takada H, Abe Y, Hara T. Cardiovascular complications associated with chronic active Epstein-Barr virus infection. Pediatr Cardiol. 2009;30(3):274-81.

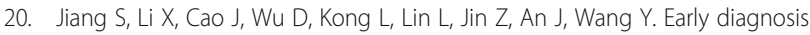
and follow-up of chronic active Epstein-Barr-virus-associated cardiovascular complications with cardiovascular magnetic resonance imaging: a case report. Medicine (Baltimore). 2016;95(31):e4384.

21. Aulagnon F, Lapidus N, Canet E, Galicier L, Boutboul D, Peraldi MN, Reuter D, Bernard R, Schlemmer B, Azoulay E, et al. Acute kidney injury in adults with hemophagocytic lymphohistiocytosis. Am J Kidney Dis. 2015;65(6):851-9.

22. Mayer HB, Wanke CA, Williams M, Crosson AW, Federman M, Hammer SM. Epstein-Barr virus-induced infectious mononucleosis complicated by acute renal failure: case report and review. Clin Infect Dis. 1996;22(6):1009-18.

23. Suzuki J, Komada T, Hirai K, Tsuruoka H, Mori H, Yoshida I, Tabei K. An adult case of fulminant Epstein-Barr virus infection with acute tubulointerstitial nephritis. Intern Med. 2012;51(6):629-34.

24. Ozgurhan G, Ozcetin M, Vehapoglu A, Karakaya Z, Aygun F. Acute kidney injury complicated Epstein-Barr virus infection in infancy. Case Rep Pediatr. 2015:2015:848959.

25. Moretti M, Lava S, Zgraggen L, Simonetti GD, Kottanattu L, Bianchetti MG, Milani GP. Acute kidney injury in symptomatic primary Epstein-Barr virus infectious mononucleosis: systematic review. J Clin Virol. 2017;91:12-7.

26. Mansur A, Little MA, Oh WC, Jacques S, Nightingale P. Howie AJ, Savage CO. Immune profile and Epstein-Barr virus infection in acute interstitial nephritis: an immunohistochemical study in 78 patients. Nephron Clin Pract. 2011; 119(4):C293-300

27. Joh K, Kanetsuna Y, Ishikawa Y, Aizawa S, Imadachi A, Tastusawa O, Ohishi T. Epstein-Barr virus genome-positive tubulointerstitial nephritis associated with immune complex-mediated glomerulonephritis in chronic active EB virus infection. Virchows Arch. 1998;432(6):567-73.

28. Araya CE, Gonzalez-Peralta RP, Skoda-Smith S, Dharnidharka VR. Systemic Epstein-Barr virus infection associated with membranous nephropathy in children. Clin Nephrol. 2006;65(3):160-4.

29. Sato Y, Furuyama K, Suzuki T, Tanaka T, Sato A, Iguchi A, Yoshita K, Ito Y, Imai $\mathrm{N}$, Yamazaki $\mathrm{H}$, et al. Acute kidney injury in an adult patient with IgA nephropathy and chronic replicative Epstein-Barr virus infection. CEN Case Rep. 2019;8(4):285-91.

30. Becker JL, Miller F, Nuovo GJ, Josepovitz C, Schubach WH, Nord EP. EpsteinBarr virus infection of renal proximal tubule cells: possible role in chronic interstitial nephritis. J Clin Invest. 1999;104(12):1673-81.

\section{Publisher's Note}

Springer Nature remains neutral with regard to jurisdictional claims in published maps and institutional affiliations.

Ready to submit your research? Choose BMC and benefit from:

- fast, convenient online submission

- thorough peer review by experienced researchers in your field

- rapid publication on acceptance

- support for research data, including large and complex data types

- gold Open Access which fosters wider collaboration and increased citations

- maximum visibility for your research: over $100 \mathrm{M}$ website views per year

At $\mathrm{BMC}$, research is always in progress.

Learn more biomedcentral.com/submissions 